\title{
A SUCCESSFUL USE OF NEW MODIFIED FEEDING PLATE FOR NEW BORN BABY WITH CLEFT PALATE
}

\author{
Mona Moustafa Ebrahim Alramady*
}

\begin{abstract}
Background: Congenital abnormality is considered the most famous abnormality that occurs in all the world. Typically, they require complex multidisciplinary treatment throughout childhood and can have lifelong medical and psychosocial implications for affected individuals.
\end{abstract}

Objective: The objective of this study was to construct a new device feeding plate for a baby who had cleft palate act as a prosthetic obturator to close the defect that occur between the naso-oral and to compare feeding device and feeding bottle for new born baby and evaluation sequence of weight gain with use of feeding prosthetic obturator.

Material and Methods: Four new born babies came to the Department of Prosthodontics, Faculty of Dentistry, Alexandria University with a palatal cleft. A feeding device was fabricated. After finishing of the prosthesis, a perforation was made in the canine region with round bur in the feeding device for attachment of dental thin wire with a thickness 0.9 . Then four babies were examined by asking their mothers to use feeding bottle and the new feeding palatal device each time with a standard amount of milk per time and a questionnaire for mothers were done.

Results: The uses of the feeding devices aids help feeding provide enough nutrition and increase weight gain decrease nasopharyngeal and otitis media infection until the surgical intervention occur to correct the defects. Data were collected and statistical analysis was done.

Conclusions: It is obvious that restoring the cleft palate by feeding device help to obtain proper nourishment for the baby. Therefore, it provides normal physical mental, psychological well-being new born baby and parents. Help normal suckling, decrease the feeding and nasal difficulties, correct tongue posture, help growth and stability of maxilla and prevent its collapse.

KEY WORDS: Maxillary defect, New device plate, Obturator, Prosthetic treatment

\footnotetext{
* Lecturer at Prosthodontics Department, Pharos University, Alexandria City, Alex., Egypt
} 


\section{INTRODUCTION}

Congenital abnormality is considered the most famous defects that occurs in all the world. Typically, they require complex multidisciplinary treatment throughout childhood and can have lifelong medical and psychosocial implications for affected individuals. The defects of the oral cavity is classified into two types according to its site into: 1) Cleft lip that take place in the maxilla as a result of failure of the maxillary and nasal processes to unit together leading to congenital abnormality of lip. 2) Cleft palate that is the results of failure of the palatal process to unit properly leading to congenital abnormality of palate. Clefts lip and palate can occur separately from each other or in conjunction with other forming inborn abnormalities ${ }^{(2-4)}$.

These types of cleft which occur in lip and palate of the mouth is one of the foremost common biological process disorder found in humans ${ }^{(5-7)}$ (incidence ranges from one in 800 to 1 in 1200 live births). Cleft palate is considered as a defect that occur at born or as inherited defects it is occur as a depression at the superior part of the mouth caused by inability of the palatal shelves to come together again absolutely along from either palatal sides and closes and united together throughout the primary months of development as an embryo ${ }^{(8,9)}$. The gap within the palatal part of the oral cavity permits opening between the nasal pathways and therefore surgical treatment is required to shut the palatal defect. Inborn abnormality cleft lip will occur alone or in association with cleft palate ${ }^{(8)}$. This is often caused by some unknown disturbances throughout embryogenesis ${ }^{\left({ }^{(}\right)}$. Cleft lip and congenital abnormality (CLP) is usually related to feeding problems, Eustachian tube pathology, middle ear effusions and infections, hearing loss, confusion in speech and dental problems ${ }^{\left({ }^{8}\right)}$. A history of congenital abnormalities for the mother and therefore the entire family of a new born may be the cause of a baby born with cleft in his lip or cleft in his palatal part of the mouth ${ }^{(4)}$. The management involves team work from varied specialties. The role of the dentist is to introduce information and communicate with the mother as well as adequate nutrition for the infant ${ }^{(10)}$. Lip surgical operation following presurgical prosthetic interference is performed after optimal jaw alignment is occurred (usually occurred at the age of 3-6 months with unilateral total clefts), there is increase the aesthetic results of the lip that corrected by surgery leading to increase in growth, providing tissues that area unit of redoubled size, a lot of vascular and easier to control.

Babies having problems in feeding due to palatal cleft, a feeding prosthetic plate is found to be the most suitable solution to obturate the defects that forming an opening between the nasopharynx and overcoming the problem of feeding. The feeding plate functions as prosthetic device obturating the communication between the mouth and nasal cavity.

Cleft lip and palate may be classified into syndromic or non-syndromic types in origin. Syndromic craniofacial abnormalities including: Down's syndrome, Apert syndrome, Waardenburg's syndrome, Treacher Collins syndrome and Pierre Robin syndrome ${ }^{(11,12)}$.

The mechanism of sucking of milk from mother required new born to have a complete lip seal around breast nipple, this is not found when new born have abnormal nasooral communication, so that they cannot get negative intraoral pressure that needed for sucking of milk which is resulted in deficiency in getting enough amount of milk, and the inability to complete sucking with decrease in weight, deficient in nutrition and growth ${ }^{(13-17)}$. Feeding in new born is also become more difficult complicated by passage of fluid from nasal opening, burping due to excessive air intake during deglutition, gagging, and prolonged feeding time ${ }^{(18,19)}$.

The problems of cleft lip and cleft palate can be corrected by surgical interference but the reconstruction of the palate is usually delayed until 
6 months to 2 years of age. Early reconstruction of palate defects may have a negative effect on the gaining weight and increase growth and development of maxilla due to the presence of scar tissue ${ }^{(20)}$ while the use of feeding plate leading to the decrease in the incidence of choking, also stop the tongue from passing into the defect, and decrease the passage of food from nasal opening and prevent the growth of palatal ${ }^{(6,21)}$. It also promote positioning of the tongue in its exact position to achieve its functional role in development and growth the jaw ${ }^{(4,22)}$. When mother sucking her baby, the oral muscle are being simulating leading to increase muscular tone and helping the correct position achieving the chewing function in the future ${ }^{(23)}$. Bönecker et al. state that infant's mandibular half in the new born is vertically short and the chin prominence is deficient. Muscles tone stimulation during breastfeeding by the mother plays important role in mandibular development, providing a suitable relationship with the maxilla ${ }^{(23)}$.

Problems associated with clefts lip and palate reacquires to be achieved for successful treatment and the adequate prosthetic rehabilitation. The feeding process by the mother is always have difficulties due to passage of food from nasal opening, and increase in air intake that need burping and choking. The mother suffering from increase in the feeding time which become longer and fatigues for her and her baby as well as mother. Early treatment in cleft lip and/or palate patients is mandatory. Normally these babies must be concerned and treated by a team work. Cleft new born babies are associated with decrease in facial development, dental complications, dental difficulties, velo-pharyngeal incomplete fusion, opening and closing mouth defect and earing problems like eustachian tube dysfunction. This is a companied with decrease speech that leads to defect in the cognitive, linguistic and emotional growth in these babies, making it delayed to early reconstruction of cleft palate ${ }^{(6)}$.

The feeding plate helps to provide division between nasopharynx opening. It helps to provide a rigid platform towards which enable the baby to press the nipple between the tongues, hard palate to get enough amount of the milk by this mechanism which is not enough at the cleft palate is wide and the nipple was hold inside the palatal defect. It also helps the increase in the development and growth on the juice by providing the tongue in its correct position helping the speech developed normally. Also, help in decreasing the passage of food into the naso-pharynx with reduction in the possibility of getting otitis media and naso-pharynhgeal infections ${ }^{(6,24)}$

\section{MATERIAL AND METHODS}

Four new born young babies were taken to the Department of Prosthodontics, Faculty of Dentistry, Alexandria University. The main complaint was difficulty in feeding and breathing. On examination and taking history, it was found that babies were born with cleft of palate and therefore, the mother had difficulty in feeding the baby. After conversation with the parents, a feeding device obturator was planned for the baby.

- Patient's preliminary impression was made with alginate (Cavex) impression material the defect was packed with gauze piece.

- A preliminary model was poured with dental stone (Kalstone, Kalabhai, India)

- Block out of undercuts was done with modeling wax (DPI, India) and a special tray was made by the use of transparent self-cure acrylic resin (DPI-RR Cold Cure, India). Numerous holes were made in custom tray.

- The custom tray was brushed with tray adhesive, rubber base was prepared to obtain secondary impression.

- The secondary impression to obtained master cast. 


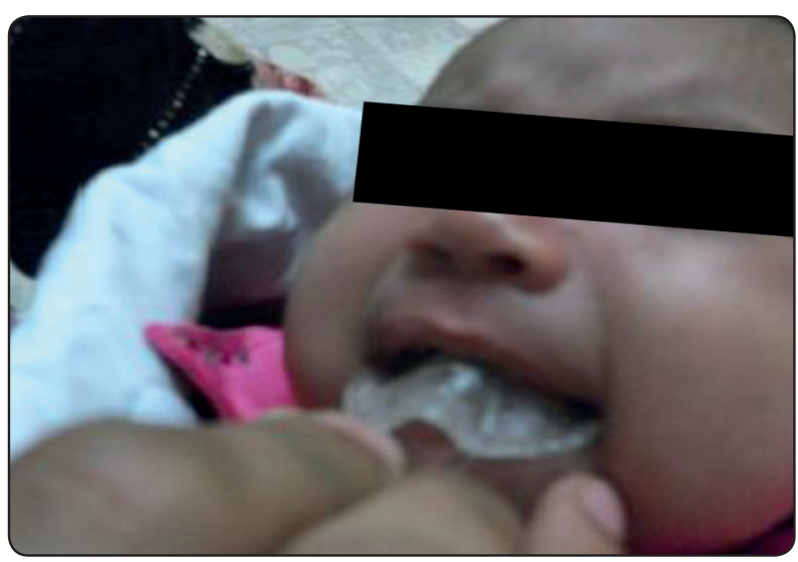

Fig. (1): Feeding appliance placed in the oral cavity of the baby

- A feeding plate device obturator was made on the master model using pressure molding technique in machine for a thickness of $1 \mathrm{~mm}$. With the used for the construction of palatal plate device used for help nutrition. Margins were trimmed with the medical scissor then finishing was done by prosthetic bur.

- After finishing of the prosthesis, a perforation was made in the canine region with round bur in the feeding device for attachment of dental thin (stainless steel 0.9) wire. Thin wire was attached to the feeding device because it prevents swallowing and allows easy retrieval of device.

- Then, the feeding device was inserted in the mouth of the infant and post insertion instructions were informed to the parents. Parents were instructed for regular follow-up. The patient was comfortable at follow-up visits, and the patient was easily fed with the device, and patient weight was increased due to proper feeding (Figures 1,2).

\section{RESULTS}

Each babies mother were instructed to use feeding bottle and the new feeding palatal device each time with a standard amount of milk per time and a questionnaire for mothers, were done.

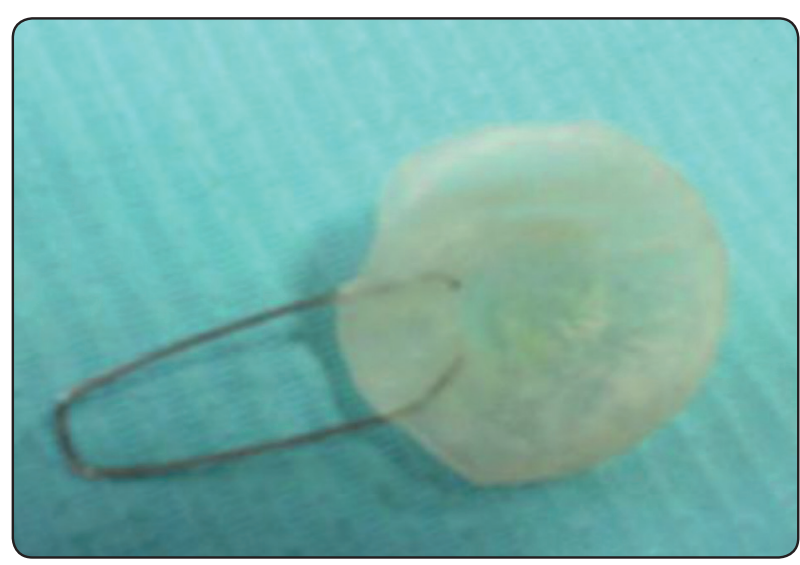

Fig. (2): Feeding appliance of ethylene vinyl acetate attached with wire

Comparison between feeding device and feeding bottle for new born baby and sequence of weight gain with use of feeding obturator were recorded. Data were collected and statistical analysis was done. (Table 1)

TABLE (1): Answers to questionnaire for the mothers about feeding methods

\begin{tabular}{|l|c|c|}
\hline \multicolumn{1}{|c|}{ Question } & Yes & No \\
\hline $\begin{array}{l}\text { Did you feeding your baby with the new } \\
\text { feeding device plate? }\end{array}$ & 4 & 2 \\
\hline $\begin{array}{l}\text { Did you prefer to feed your baby with a new } \\
\text { device plate or without it? }\end{array}$ & 1 & 5 \\
\hline Did you try to breast feeding your baby? & 2 & 4 \\
\hline $\begin{array}{l}\text { Did you found any problem in the amount of } \\
\text { milk during feeding the baby? }\end{array}$ & 4 & 2 \\
\hline $\begin{array}{l}\text { Did you found any problem in the time of } \\
\text { milk during feeding the baby? }\end{array}$ & 5 & 1 \\
\hline $\begin{array}{l}\text { Did you found any difficulty in using one of } \\
\text { the methods of feeding and try to change to } \\
\text { the other? }\end{array}$ & 3 & 3 \\
\hline $\begin{array}{l}\text { Did you found any inadequate information for } \\
\text { using any of the two methods? }\end{array}$ & 1 & 5 \\
\hline
\end{tabular}

In comparison between feeding device and feeding bottle for new born baby, it is found that at delivery the use of feeding device was decrease than feeding bottle and increase gradually at delivery, 1,2, 3, 4, 6 weeks than feeding bottle. (Table 2, Figure 3) 
In resulted Sequence of weight gain with use of feeding obturator, it was showed that the use of feeding obturator has increase gradually and resulted in gain of weight and help growth at a period of 1-3, 3-6 and 6-9 months which show that $(570,1700$ and $1800 \mathrm{gm}$ ) while decrease at the age of 9-12 months which show $1600 \mathrm{mg}$. after that at the age of 1215 months it show gradual increase (1750 gm). (Table 3, Figure 4)

The uses of the feeding devices aids help feeding speech enough nutrition and increase weight gain decrease nasopharyngeal and otitis media inflammation that may occur before the prosthetic surgical intervention occur to correct the defects.

TABLE (2): Comparison between feeding device and feeding bottle for new born baby.

\begin{tabular}{|l|c|c|}
\hline & Yes & No \\
\hline At delivery & 2 & 4 \\
\hline After one week & 5 & 1 \\
\hline After two weeks & 4 & 2 \\
\hline After three weeks & 5 & 1 \\
\hline After four weeks & 5 & 1 \\
\hline After six weeks & 6 & 0 \\
\hline
\end{tabular}

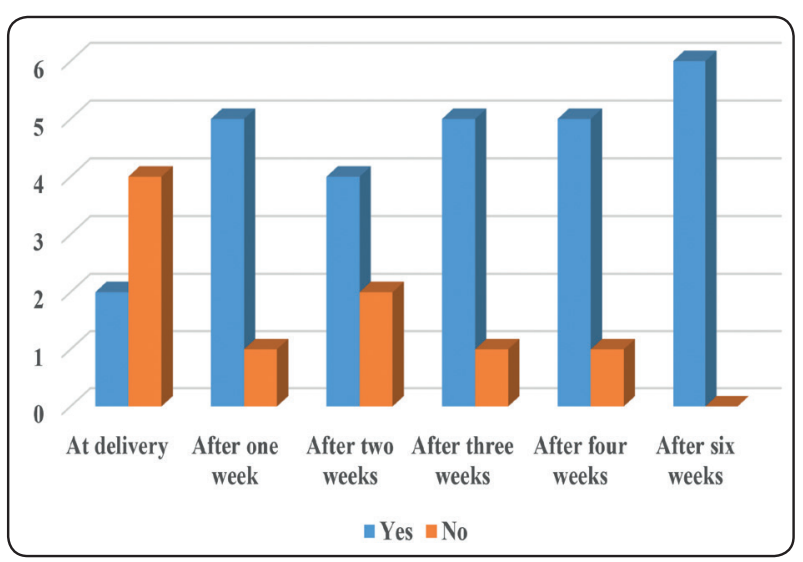

Fig. (3) Comparison between feeding device and feeding bottle for new born baby
TABLE (3): Sequence of weight gain with use of feeding obturator

\begin{tabular}{|l|c|}
\hline \multicolumn{1}{|c|}{ Age (month) } & Weight gain (gm) \\
\hline $1-3$ months & $750 \mathrm{gm}$ \\
\hline $3-6$ months & $1700 \mathrm{gm}$ \\
\hline $6-9$ months & $1850 \mathrm{gm}$ \\
\hline $9-12$ months & $1600 \mathrm{gm}$ \\
\hline $12-15$ months & $1750 \mathrm{gm}$ \\
\hline
\end{tabular}

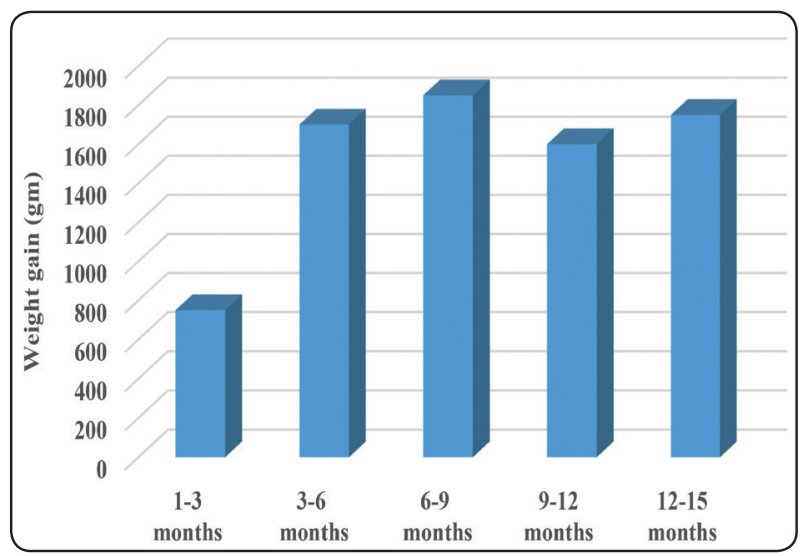

Fig. (4): Sequence of weight gain with use of feeding obturator

\section{DISCUSSION}

From the majority of abnormalities occur in new born are cleft lip and cleft palate presented in the orofacial region and the nasopharynx communication presented due to the palatal defect a great problems for the newborn which inhibit the proper suckling of milk and inability to produce a sound and this may affect all physical and mental growth and progress of the baby. The feeding plate act as a prosthetic obturator to restore such defect. It closes the nasopharynx opening and helps the process of nutrition for the baby. Our study describes the prosthetic treatment of the newborn with cleft palate by fabrication of feeding plate. 
Enough nutrition is the most important priority in patients with cleft lip and palate, and the method used should be found so that feeding is considered as normal breastfeeding as possible ${ }^{(25)}$.

Neonates with a cleft in the palate have difficulty in eating, which may lead to failure to thrive. The oronasal communication leads to a diminished the probability to get negative pressure that is required for suckling ${ }^{(4)}$ that help the baby to positioning the nipple of mother to get between his tongue and the palate, but this technique is also ineffective if cleft is wide. The passage of food from nasal opening, excessive air intake and other prolonged feeding time are other frequent complications ${ }^{(6,21,26)}$.

A disadvantage of the feeding palatal device obturator is that the baby cannot push the palate while swallowing because of the presence of the feeding device plate which is the rigid pulp. It also helps to determine the suitable space needed between the palatal device and pharyngeal wall that help in prevention of his regurgitation. In this case, the new born could swallow more than $60 \mathrm{ml}$ of milk during each one feeding with the feeding obturator plate installed. While before its use, it was only $10-15 \mathrm{ml}$. We would like to relign the feeding plate every month to adjust for the infant's growing $\operatorname{maxilla}^{(27)}$.

However, the prosthetic treatment is achieved as a first solution before presurgical treatment which can achieved only at the age between 6 and 12 months of age. So, prosthetic treatment is an initial solution prior to surgical treatment.

Mother needs to be awareness about modifications of the new position for feeding her baby. Football hold position is a modified one (holding the baby at an angle of $45^{\circ}$ ), which decrease passage of food from nasal opening (6). Also, palatal plate help in providing relief to the baby make modification for nipple model by pressing on it leading to squeeze bottles and so the nipple's bottles will have large openings etc ${ }^{(28)}$. These devices when inserted on the palatal defect of the infant completes the seal of the oral opening providing pressure suitable to enabling he feeding of the baby and reducing nasal passage of food and decrease the time needed for feeding ${ }^{(4,22,25,28,29)}$.

The use of feeding device in cleft patients is a valuable solution and it greatly assists in direct breast feeding.

Advantages of using a feeding device includes Following ${ }^{27,30)}$ :

1. It helps to provide enough nutrition by closing the opening between palate and oral cavity with the rigid plate obturator, so the new born baby can suck normal amount of feeding milk which helps in increase growth and development.

2. Reducing the complication of passage of food from nose and reduce time of feeding helping the tongue to be in a correct positioned.

3. By positions of the tongue in correct posture will prevent it to enter into the defect, thus helps in the growth of maxilla and the maxillary shelves toward each other.

4. Reduces the ability to produce a nasopharyngeal infections and otitis media due to passage of milk.

5. It also helps in presurgical nasoalveolar molding.

6. Help cross arch stability and the presence of maxillary arch collapse.

Fabrication of feeding device in a newborn poses unique set of challenges including the size constraints of the oral cavity, variation in size, location, and the exaggerated extension of the palatal cleft, infant's inability to cooperate and follow commands.

Our study also agrees with Surya et al. ${ }^{(31)}$, who study prosthetic management of malnourished new baby with cleft in the palate using a feeding plate device. They showed that Prosthetic management of malnourished infant with cleft in the palate using a feeding plate device. 
Goyal et al. ${ }^{(32)}$, in evaluating the role of obturators and other feeding interventions in patients with cleft in the lip and associated with cleft palate found that in case of babies with CLCP would fulfill the feeding requirements of such babies by the using of different interventions like palatal device obturator, Haberman feeder, and breast milk using pump aids and lactation education are usually excellent to meet the feeding needs of both mother and child.

Rathee et al. ${ }^{(6)}$, concluded that for stumbling blocking milestones of normal development which was inserted as early as possible after baby born which is achieved by using of feeding palatal obturator. It help for perfect nursing and promoting of oro-facial muscle therapy to help their growing and stimulation. This will help palatal half to grow and prevent tongue inability to functional perfectly and the septum of the nose will be prevented from irritation and decrease the infections that may occur in the middle ear, also help in the expanding the collapsed maxillary half, which will help the team of health care specialist and physiological help to the parents.

In a previous study, Atito ${ }^{(24)}$, described comparison of different kinds of palatal feeding device obturators: 1) Feeding bottle, 2) Feeding obturators, because it affective in overcoming feeding problems associated with cleft palate. Readymade obturator is less feeding time then feeding bottle.

In a previous study, for evaluating Awareness of feeding plates among the parents of cleft in the lip and palatal palate device for children in Kashmiri population-an original research, it was concluded that in our society due to lack of awareness in parents and regarding feeding plates, mostly parents do not approach prosthodontic for treatment of their neonates. So, a need exists to address this problem by organising campaigns and make people to be interested of these options in this part of valley ${ }^{(33)}$.
Naveen et al. ${ }^{(34)}$, concluded that insufficient nutrition not only affect growing of the child by also caused anxiety of their parents so it is important to use feeding plate device as obutrator to achieve good feeding which help to provide enough nutrition to increase weight, decrease infection to ear and nasopharyngeal so surgical treatment for interference to correct the defect is carried out which resulted to achieve normal psychological, physical and mental effect ${ }^{(35,36)}$.

Kumar, et al. ${ }^{(37)}$, in a previous study for evaluation of feeding practice in infants with cleft in the lip and palate at cleft centers concluded that the most famous feeding achieved by the parents of cleft in the lip and palate new born as per introduced and suggested by Sangu/Paladai. This method was a companied by the use of feeding methods of every 2 hours in an upright position. Overall, a lack of knowledge regarding the feeding plate and referral to the pediatric dentist was observed.

The main important aim for new born with cleft in the lip and palatal cleft is a good nutrition, so the techniques should be presented so that feeding is as nearly close to normal breastfeeding as possible.

Advantage of adding stainless steel wire to the device that it can be easily adapted and molded to the soft smooth skin of the born baby and the mother can control the use of it.

\section{Advantages of using feeding device include:}

1. It provide adequate nutrition through covering the palatal cleft and giving a rigid platform by which the new born can suckling the milk by pressing the nipple of the mother breast.

2. It helps the normal suckling which leads to normal development of the oromotor receptors and swallowing of food reflexes.

3. Decrease the problems which may resulted as passage of food from nasal opening, suffocating, and decrease the feeding time. 
4. Promote the development of maxilla and maxillary parts to come together toward each other by positioning of the tongue in its correct position.

5. Decrease the infection of nasopharyngeal area and otitis media through decrease the milk passage into it.

6. Help nasoalveolar corrected position before surgery.

7. It provides cross arch stability and prohibit maxillary arch collapse after plastic surgery intervention.

\section{CONCLUSIONS}

Feeding plate obturator helps in preservation of the masticatory and deglutition functions promote speech till the cleft in the lip and/or palate can be corrected by surgical intervention. Methods for construction of feeding plate obturator are described.

It is important to restore the cleft palate by feeding device to obtain proper nourishment for the baby due to difficulty in feeding and the accurate nutrition is important to help achieve exact standard needed for increase growth and successful development of the baby so the feeding plate should be fabricated as fast as possible after the baby so that its growth will take place successfully and their development are not affected.

The child needed enough amount of milk to achieve exact standard needed for increase growth and successful development of the newborn and also overcome the problems that may affect the parents. The use of the feeding palatal plate aids help feeding speech enough nutrition and increase weight gain decrease nasopharyngeal infection and otitis media until the surgical approach occur to correct the defects. There for it provide normal physical mental, psychological well-being new born baby and parents.
Help normal suckling, decrease the feeding and nasal difficulties, correct tongue posture, help growth and stability of maxilla and prevent its collapse.

The future study needed to be made to increase patient's awareness about the use of feeding plate as a prosthetic approach to solve the problem of feeding new born.

\section{CONFLICT OF INTEREST}

The authors declare that they have no conflict of interest.

\section{REFERENCES}

1. Abu-Hussein M. Cleft Lip and Palate-Etiological Factors . Dent Med Probl. 2012;49:149-56.

2. Muhamad AH, Azzaldeen A. Genetic of Non-syndromic Cleft Lip and Palate. 2012;1:510.

3. Abu-Hussein M. Cleft lips and palate; the roles of specialists. Minerva Pediatr. 2011;63:227-32.

4. Abu-Hussein M, Watted N, Emodi O, Zere E. Role of pediatric dentist - orthodontic in cleft lip and cleft palate patients. IOSR-JDMS. 2015;14:61-8

5. Radhakrishnan J, Sharma A. Feeding plate for a neonate with Pierre Robin sequence. J Indian Soc Pedod Prev Dent. 2011;29:239-43.

6. Rathee M, Hooda A, Tamarkar AK, Yadav S. Role of feeding plate in cleft palate: Case report and review of literature. Internet J Otorhinolaryngol. 2010;12:1-6.

7. Goel D, Goel GK, Jain D. Fabrication of feeding device for a four -day old infant - A case report and discussion. Int $\mathrm{J}$ Dent. 2015;7:2.

8. Padawe DS, Takate VS. Management of an infant with Veau's Class IV Cleft: A Case Report. GDC Mumbai 2015

9. Savion I, Michael L. Huband A feeding obturator for a preterm baby with Pierre Robin sequence. J Prosthet Dent. 2005;93:197-200.

10. Singla S. Cleft palate habilitation. Indian J Pediatr. 2008;75:703-8.

11. Habel A, Sell D, Mars M. Management of cleft lip and palate. Arch Dis Child. 1996;74:360-6. 
12. Kirschner RE, LaRossa D. Cleft lip and palate. Otolaryngol Clin North Am. 2000;33:1191-215.

13. Masarei AG, Sell D, Habel A, Mars M, Sommerlad BC, Wade A. The nature of feeding in infants with unrepaired cleft lip and/or palate compared with healthy noncleft infants. Cleft Palate Craniofac J. 2007;44:321-8.

14. Clarren SK, Anderson B, Wolf LS. Feeding infants with cleft lip, cleft palate, or cleft lip and palate. Cleft Palate J. 1987;24:244-9.

15. Choi BH, Kleinheinz J, Joos U, Komposch G. Sucking efficiency of early orthopaedic plate and teats in infants with cleft lip and palate. Int J Oral Maxillofac Surg. 1991; 20:167-9.

16. Reid J. A review of feeding interventions for infants with cleft palate. Cleft Palate Craniofac J. 2004;41:268-78.

17. Reid J, Reilly S, Kilpatrick N. Sucking performance of babies with cleft conditions. Cleft Palate Craniofac J. 2007;44:312-20

18. Arvedson J, Brodsky L. Feeding with craniofacial anomalies: An interdisciplinary Approach. Louis Mosby. 1992; 12:527-59.

19. Shetty MS, Khan MB. Feeding consideration in infants born with cleft lip and palate. APOS Trends Orthod. 2016;6:49-53.

20. Lodaya R, Dave A, Kunte S, Kumar S, Kalavathi SD, Laishram N. A feeding device for a 2 day old neonate with cleft lip and palate: A case report. Int J Oral Health Med Res. 2017;3:86-9.

21. Rathee M, Tamrakar AK. Single visit custom made flexible feeding obturator for an infant with tetralogy of fallot. Saudi J Med Med Sci. 2015;3:226-9.

22. Muhamad AH, Azzaldeen A, Watted N. Cleft lip and palate: A comprehensive review. IJBAS. 2014;4:338-55.

23. Ross RB. Treatment variables affecting facial growth in complete unilateral cleft lip and palate. Cleft Palate J. $1987 ; 24: 5-77$

24. Atito EM. Comparison between two types of feeding obturators in cleft palate babies. ADJ-for Grils. 2017; 4:297-301.

25. Agarwal A, Rana V, Shafi S. A feeding device for a newborn baby with cleft lip and palate. Natl J Maxillofac Surg. 2010;1:91-3.
26. Goswami M, Jangra B, Bhushan U. Management of feeding problem in a patient with cleft lip/palate. Int J Clin Pediatr Dent. 2016;9:143-5.

27. Jones JE, Henderson L, Avery DR. Use of a feeding Obturator for infants with severe cleft lip and palate. Spec Care Dentist. 1982;2:116-20

28. Malik P, Aggarwal A, Ahuja R. Feeding device for an infant with cleft lip and palate. Pak Oral Dental J. 2012;32:264-6.

29. Osuji OO. Preparation of feeding Obturator for infants with cleft lip and palate. J Clin Pediatric Dent. 1995;19:211-4.

30. Akulwar R. Feeding plate for the management of neonate born with cleft lip and palate. Int J Sci Res. 2014;3:362-4.

31. Surya R. Prosthetic management of malnourished infant with clef $t$ palate using a feeding plate device-A Case report. TPDI. 2020;7:32-4.

32. Goyal M, Chopra R, Bansal K, Marwaha M. Role of obturators and other feeding interventions in patients with cleft lip and palate: a review. Eur Arch Paediatr Dent. 2014;15:1-9.

33. Naz F, Mir S, Bali SK, Nazir S. Awareness of feeding plates among the parents of cleft lip and palate children in Kashmiri population-an original research. AGE. 2018;32:17.

34. Naveen BH, Prasad RS, Kashinath KR, Kumar S, Kalavathi $\mathrm{SD}$, Laishram N. An innovative modified feeding device for an infant with cleft lip and cleft palate: A case report. J Family Med Prim Care. 2019;8:2134-6.

35. Kochel J, Meyer-Marcotty P, Wirbelauer J, Böhm H, Kochel M, Thomas W, et al. Treatment modalities of infants with upper airway obstruction--review of the literature and presentation of novel orthopedic devices. Cleft Palate Craniofac J 2011;48:44-55.

36. Dogra S, Sharma A, Sharma N. Early prosthetic rehabilitation in newborns with orofacial cleft using a feeding device: A case report and review of literature. J Indian Acad Dent Spec Res. 2017;4:5-11.

37. Kumar SM, Vankayala B, Kumar M, Gudugunta L, Basavarajaiah JM, Umayal M. Evaluation of Feeding Practice in Infants with Cleft Lip and Palate at Cleft Centers. EC Dent Sci. 2019;18:1420-7. 